University of Rhode Island

DigitalCommons@URI

Cancer Prevention Research Center Faculty

Publications

Cancer Prevention Research Center

2015

\title{
Predictors of relapse among smokers: Transtheoretical effort variables, demographics, and smoking severity
}

\author{
N. S. Gökbayrak \\ University of Rhode Island \\ Andrea L. Paiva \\ University of Rhode Island, apaiva@uri.edu \\ Bryan J. Blissmer \\ University of Rhode Island, bblissme@uri.edu \\ James O. Prochaska \\ University of Rhode Island, joprochaska@uri.edu
}

Follow this and additional works at: https://digitalcommons.uri.edu/cprc_facpubs

This is a pre-publication author manuscript of the final, published article.

Creative Commons License

c) (†) $\odot$

This work is licensed under a Creative Commons Attribution-Noncommercial-No Derivative Works 4.0 License.

\section{Citation/Publisher Attribution}

Gökbayrak, Paiva, A. L., Blissmer, B. J., \& Prochaska, J. O. (2015). Predictors of relapse among smokers: Transtheoretical effort variables, demographics, and smoking severity. Addictive Behaviors, 42, 176-179. doi: 10.1016/j.addbeh.2014.11.022

Available at: https://doi.org/10.1016/j.addbeh.2014.11.022

This Article is brought to you for free and open access by the Cancer Prevention Research Center at DigitalCommons@URI. It has been accepted for inclusion in Cancer Prevention Research Center Faculty Publications by an authorized administrator of DigitalCommons@URI. For more information, please contact digitalcommons-group@uri.edu. 


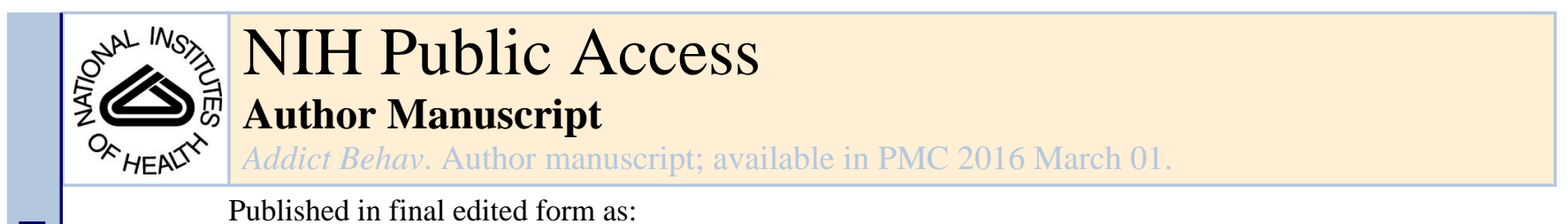

Published in final edited form as:

Addict Behav. 2015 March ; 0: 176-179. doi:10.1016/j.addbeh.2014.11.022.

\title{
Predictors of relapse among smokers: Transtheoretical effort variables, demographics, and smoking severity
}

\author{
N. S. Gokbayrak ${ }^{1}$, A. L. Paiva1 ${ }^{1}$, B. J. Blissmer ${ }^{2}$, and J.O. Prochaska ${ }^{1}$ \\ ${ }^{1}$ Cancer Prevention Research Center, University of Rhode Island, Kingston, RI \\ ${ }^{2}$ Department of Kinesiology, University of Rhode Island, Kingston, RI
}

\section{Abstract}

The present longitudinal study investigates baseline assessments of static and dynamic variables, including demographic characteristics, smoking severity, and Transtheoretical Model of Behavior Change (TTM) effort variables (Decisional Balance (e.g. Pros and Cons), Situational Temptations, and Processes of Change) of relapse among individuals who were abstinent at 12-months. The study sample $(\mathrm{N}=521)$ was derived from an integrated dataset of four population-based smoking cessation interventions. Several key findings included: Participants who were aged 25-44 and 45$64(\mathrm{OR}=.43, p=.01$ and $\mathrm{OR}=.40, p=.01$, respectively) compared to being aged 18-24 were less likely to relapse at follow-up. Participants in the control group were more than twice as likely to relapse ( $\mathrm{OR}=2.17, p=.00)$ at follow-up compared to participants in the treatment group. Participants who reported higher Habit Strength scores were more likely to relapse ( $\mathrm{OR}=1.05, p$ $=.02)$. Participants who had higher scores of Reinforcement Management $(\mathrm{OR}=1.05, p=.04)$ and Self-Reevaluation ( $\mathrm{OR}=1.08, p=.01)$ were more likely to relapse Findings add to one assumption that relapsers tend to relapse not solely due to smoking addiction severity, but due to immediate precursor factors such as emotional distress. One approach would be to provide additional expert guidance on how smokers can manage stress effectively when they enroll in treatment at any stage of change.

\section{Keywords}

smoking; relapse; maintenance; stage of change; transtheoretical model; processes of change; pros and cons; self-efficacy; temptations

(C) 2014 Elsevier Ltd. All rights reserved.

Correspondence to: N. Simay Gokbayrak, M.A., Cancer Prevention Research Center, 2 Chafee Road, University of Rhode Island, Kingston, RI 02881. Tel. 401-874-5435; Fax. 401-874-4215; simaygokbayrak@ gmail.com.

Author Disclosures

This study was supported by the NIH P01-CA050087 Grant. The funding agency had no role in the design and conduct of the study; the collection, management, analysis, or interpretation of the data; or the preparation of the manuscript. Authors Gokbayrak, Paiva, Blissmer and Prochaska designed the study. Authors Gokbayrak and Paiva conducted the statistical analysis. Author Gokbayrak wrote the first draft of the manuscript and all authors contributed to and have approved the final manuscript. All authors declare that they have no conflicts of interest. The authors wish to thank Ms. Hui-Qing Yin, M.A., who assisted in data analysis.

Publisher's Disclaimer: This is a PDF file of an unedited manuscript that has been accepted for publication. As a service to our customers we are providing this early version of the manuscript. The manuscript will undergo copyediting, typesetting, and review of the resulting proof before it is published in its final citable form. Please note that during the production process errors may be discovered which could affect the content, and all legal disclaimers that apply to the journal pertain. 
Smoking continues to be the leading cause of preventable disease, general morbidity, and mortality in the United States (CDC, 2010). Before becoming completely abstinent, most smokers make a number of quit attempts (between 4 and 14) (CDC, 2013; Kaida, Edwards, Fraser-Lee, Kunyk et al., 2004) making relapse a common factor within the behavior change process (e.g. DiClemente, 2006). Although relapse is prevalent, most smoking cessation interventions group relapsers with those who never quit in their final analyses. This ignores a potentially important subgroup from a public health perspective (Sun, Prochaska, Velicer \& Laforge, 2007).

Utilizing a Transtheoretical Model of Behavior Change (TTM) framework provides a theoretical guide for examining how relapsers differ from individuals that never quit. The TTM is organized around individuals' Stage of Change, or their readiness to change a target behavior. Readiness to change a behavior (i.e. smoking cessation) is mediated by three core constructs or "effort" variables: Decisional Balance, Situational Temptations, and Processes of Change. Decisional Balance refers to an individual's perception of the importance of the Pros vs. the Cons of smoking. Situational Temptations assess how tempted people are to engage in smoking in specific situations. Processes of Change are the frequency with which an individual engages in ten specific cognitive and behavioral activities that have been shown to facilitate forward movement through the stages.

Significant predictors of successful cessation/abstinence have been found to include smoking addiction severity, age, education (Velicer, Redding, Sun, \& Prochaska, 2007), and Stage of Change and TTM effort variables (e.g. Redding, Prochaska, Paiva, Rossi et al., 2011; Blissmer, Prochaska, Velicer, Redding et al., 2010). In order to better serve the full population of smokers, a more comprehensive understanding of static and dynamic variables that could differentiate those who relapse from those who stay quit could provide insights for improving tailored cessation interventions. As such, the present study aimed to determine which of the variables (demographic, smoking severity and TTM effort) could best predict relapse at 24 months among past smokers that were quit at 12 months.

\section{Methods}

\section{Intervention}

This study involved secondary data analysis on a combined dataset of four population-based studies (Prochaska et al., 2001; Prochaska et al., 2004; Prochaska et al., 2005; Velicer et al., 2004). All four studies used a common TTM-tailored expert system intervention that was printed and delivered to participants' homes. Participants also received stage-matched selfhelp manuals. Control groups received assessments only. Participants were assessed at 6 month intervals post-baseline through 30 months.

\section{Participants}

The original four studies recruited only current smokers (in the pre-Action stages) at baseline. Since the intention of the present study is to examine relapse, participants in the Action/Maintenance stages at 12 months post-baseline $(\mathrm{N}=661)$ and who had complete data at 24-months post-baseline ( $\mathrm{N}=521)$ were included. Participants who reported that they were 
in any of the pre-Action stages (Precontemplation, Contemplation, or Preparation) at 24months were classified as relapsers, and those who were in Action/Maintenance at 24months were classified as maintainers.

\section{Measures}

Severity of Smoking - Number of cigarettes smoked daily and time to first cigarette, two main parts of the Fagerstrom index that reflect the degree of addiction were assessed (Fagerstrom, Heaherton, \& Kozlowski, 1990) in addition to previous longest quit attempt in months and number of quit attempts in the past year.

Stage of Change-An algorithm assessed a participant's readiness to quit smoking, with response options of $1=$ Precontemplation (not intending to quit smoking within the next six months), 2=Contemplation (intending to use the quit smoking within the next 6 months), $3=$ Preparation (intending to use the quit smoking within the next 30 days), $4=$ Action (quit smoking within the last six months), and 5=Maintenance (quit smoking more than six months ago) (Prochaska \& DiClemente, 1992).

Decisional Balance-An 8-item decisional balance measure assessed the relative importance of various advantages (Pros) and disadvantages (Cons) in an individual's decision to smoke. Participants were asked to rate the importance of each item on a 5-point Likert scale, ranging from 1 = "Not At All Important" to 5 = "Extremely Important" (Velicer et al., 1985).

Situational Temptation-A 9-item measure assessed the intensity of urges to engage in smoking when faced with difficult situations. Psychometric analysis revealed a hierarchical structure with three first-order factors: Positive Social, Negative Affect, and Habit Addictive (Velicer et al., 1990). The higher the self-efficacy individuals have, the lower are their temptations. Participants rated their confidence to be able to quit smoking in the presence of temptations on a 5-point Likert scale ranging from 1= "Not At All Tempted" to 5= "ExtremelyTempted" (Velicer et al., 1990; DiClemente, 1986, 1981).

Processes of Change-This measure (Fava, Rossi, Velicer, \& Prochaska, 1991) evaluates 10 processes using a five-point Likert scale of frequency of use in the past month $(1=$ Never to $5=$ Repeatedly $)$. Confirmatory factor analysis supported the 10 -process measurement model (Prochaska, et al., 1988), with two higher order factors of five processes each labeled: experiential and behavioral.

\section{Results}

Approximately half of the sample was female (58.7\%), with a mean age of 41.45 (SD = 13.45). The majority of the sample was White (95.9\%) and married or living with a partner $(65.9 \%)$, and about half of the sample having some high school education or holding a high school diploma (52.4\%). There were no significant differences between treatment and control groups on any of the demographic characteristics (i.e. gender, age, race, education, marital status). There was a significant difference between groups for time until first cigarette, with the treatment group having significantly more participants waiting more than 
10 hours to smoke their first cigarette of the day $(8.1 \%)$ than the control group $(2.3 \%)\left(\chi^{2}\right.$ $(1)=13.92, p<.01)$. There was also a significant difference between groups for longest quit attempt, with the treatment group having significantly more participants with their longest quit attempt range between 36-72 months $(17.5 \%)$ than the control group $(6.3 \%)\left(\chi^{2}(1)=\right.$ $19.68, p<.001)$.

Crosstabs indicated that $35.0 \%$ of the control group (total $\mathrm{N}=300$ ) participants relapsed, while $19.9 \%$ of the treatment group (total $\mathrm{N}=221$ ) participants relapsed at follow-up. There was a statistically significant relationship between being in the treatment group and relapsing compared to maintaining at 24-months $\left(\chi^{2}(1)=14.19, p=.00\right)$. Odds ratios for baseline demographic variables and severity of smoking variables, and TTM effort variables, are presented in Tables 1 and 2, respectively.

\section{Discussion}

The primary goal and strength of this study was to explore static as well as dynamic variables as potential predictors of relapse within a multivariate and longitudinal study design. The majority of participants (71.4\%) who quit at 12 months maintained at 24 months. As expected, being in a control group was a salient predictor of relapse. Only age was a predictor of relapse with participants aged 25-64 less likely to relapse than participants aged 18-24. Nationally, this period of human development (i.e., ages 18-24) has the highest rates of smoking, as well as intense psychological distress (CDC, 2012), and appears most likely to increase relapse risk even if we can encourage a quit attempt.

In line with previous findings (Velicer et al., 1990) the psychological aspects of smoking severity assessed by Habit Strength as well as the Total Situational Temptations predicted that those who scored higher were more likely to relapse at follow-up. Yet, there were no similar effects with the conventional ways of assessing smoking severity based on daily cigarette use and time until first cigarette. The discrepancy in findings between the two ways of measuring addiction severity indicate that a more comprehensive way of assessing addiction via immediate emotional and social factors, also termed as "process-situational," an approach pioneered by Martlatt and Gordon (1985), may better capture mechanisms of relapse. Furthermore, this finding supports that relapsers tend to relapse not solely due to smoking addiction severity, but due to immediate precursor factors such as emotional distress (e.g. Shiffman \& Waters, 2004).

Previous quit attempts suggest interesting patterns, with those who had been quit between 36-72 months in the past being less likely to relapse compared to those who had only been quit for a month. However, it was also observed that those who made 3-10 quit attempts in the past compared to none were more likely to relapse.

Based on the significance of the Total Situational Temptations score finding, positive social experiences related to smoking, in which a positive affective component (e.g. socializing) is present, also can instigate relapse (Velicer et al., 1990). Pros and Cons did not differentiate between relapsers and maintainers. Pros and cons are most important in preparing individuals to take action but not for maintaining that action. 
Similar to what has been found in previous studies (Redding et al., 2011; Sun et al., 2007), Self-Reevaluation (SR) was a key process that differentiated relapsers from maintainers. Those studies have indicated that once individuals quit, they benefit from decreasing their reliance on SR and increasing their utilization of Behavioral Processes such as Helping Relationships for potential stress management and support, and Stimulus Control for alteration of environmental cues to maintain the cessation process. Typically, SR has been shown to be utilized as one is getting prepared to quit smoking. It is a process that allows an individual to realize that quitting smoking goes beyond just changing behavior but that it can be an important part of their identity.

PRIME Theory (West, 2006) proposes that establishing a "strong non-smoker" identity may be an important factor protecting against the situational temptation to smoke that could lead to relapse (Vangeli, Stapleton, \& West, 2010). A preliminary study (Vangeli et al., 2010) found that identity became more established over time as a smoker and raised the question of whether the process of identity change from a smoker to a non-smoker might be expected to take longer among those with a more extensive smoking history. If that is, in fact, seen in replication studies, helping smokers toward a strong "non-smoker" identity through use of SR may be a useful goal in future tailored interventions to prevent relapse.

One other process, Reinforcement Management (RM) was a significant predictor of relapse. $\mathrm{RM}$, a behavioral process, has been found to be utilized when taking action to quit (e.g., rewarding one's self or being rewarded by others for making changes). Although practicing RM can encourage someone to quit, it may not be sufficient for maintenance as that process entails an omission of a behavior (e.g. not smoking) rather than the active participation in a new behavior.

This study had several limitations. Although sample characteristics were representative of the larger population-based clinical trial, homogeneity of race limits generalizability of findings. Second, the long recall period between baseline and prior years allows for potential recall bias about quit attempts and prior smoking behavior (Gilpin \& Pierce, 1994).

Additionally, relapsers were evaluated at one time point only. Looking at relapsers at multiple timepoints likely will add to the literature. It is also important to note that given that an odds ratio is reflective of a one unit increase in the dependent variable, dichotomization may have inflated classification (e.g. treatment vs. control group).

Our findings add to the literature that relapse may be much more of an affective and situational process among smokers. Studies suggest that nicotine craving, an intense desire to smoke, typically lasts around 5-12 minutes, and that cravings, as well as increases in smoking rate and nicotine intake are highly related to acute physical or psychological stress (e.g. al'Absi, Wittmers, Erickson, Hatsukami, \& Crouse, 2003). The interaction between craving and stress is important to examine, since stress-induced craving states have been associated with relapse ( $\mathrm{Ng} \&$ Jeffery, 2003). As such, one approach would be to provide additional expert guidance on how smokers can manage stress effectively when they enroll in treatment at any Stage of Change. Future research needs to find ways to capitalize on TTM variables over the course of the intervention, as well as after treatment ends given that smoking cessation warrants a lifelong commitment. 


\section{References}

al'Absi M, Wittmers LE, Erickson J, Hatsukami D, Crouse B. Attenuated adrenocortical and blood pressure responses to psychological stress in ad libitum and abstinent smokers. Pharmacology Biochemistry and Behavior. 2003; 74:401-410.

Blissmer B, Prochaska JO, Velicer WF, Redding CA, Rossi JS, Greene GW, Paiva A, Robbins M. Common factors predicting long-term changes in multiple health behaviors. Journal of Health Psychology. 2010; 15:205-214.10.1177/1359105309345555 [PubMed: 20207664]

Centers of Disease Control and Prevention. Tobacco use cessation. 2013. Accessed at: http:// www.cdc.gov/workplacehealthpromotion/implementation/topics/tobacco-use.html

Centers of Disease Control and Prevention. 2012 Surgeon General's Report-Preventing Tobacco Use Among Youth and Young Adults. 2012. Accessed at: 0http://www.cdc.gov/tobacco/ data_statistics/sgr/2012/consumer_booklet/pdfs/consumer.pdf

Centers for Disease Control and Prevention. Cigarette smoking among adults - United States, 2007. Morbidity and Mortality Weekly Report. 2010; 57:1221-1226.

DiClemente CC. Self-efficacy and the addictive behaviors. Journal of Social and Clinical Psychology. 1986; 4:302-315.

DiClemente CC. Self-efficacy and smoking cessation maintenance: A preliminary report. Cognitive Therapy and Research. 1981; 5:175-187.

DiClemente, CC. Addiction and change: How addictions develop and addicted people recover. NY: The Guilford Press; 2006.

Fagerstrom KO, Heaherton TF, Kozlowski LT. Nicotine addiction and its assessment. Ear Nose Throat Journal. 1990; 69:763-765.

Fava, JL.; Rossi, JS.; Velicer, WF.; Prochaska, JO. Structural confirmation of short form instruments for the Transtheoretical model. Paper presented at the 99th Annual Convention of the American Psychological Association; San Francisco, CA. 1991 Aug.

Gilpi E, Pierce JP. Measure smoking cessation: Problems with recall in the 1990 California Tobacco Survey. Cancer Epidemiology, Biomarkers \& Prevention. 1994; 3(7):613-617.

Kaida, A.; Edwards, J.; Fraser-Lee, N.; Kunyk, D.; Lightfoot, P.; Marko, J.; Spence, JC.; Spinola, C. Smoking in the Capital Health region - Report, Population Health Survey 2002. Edmonton, Alberta: Capital Health; 2004.

Martlatt, GA.; Gordon, JR. Relapse prevention. New York: Guilford Press; 1985.

$\mathrm{Ng}$ DM, Jeffery RW. Relationships between perceived stress and health behaviors in a sample of working adults. Health Psychology. 2003; 22(6):638-642. [PubMed: 14640862]

Prochaska, JO.; DiClemente, CC. Stages of change in the modification of problem behaviors. In: Hersen, M.; Eisler, RM.; Miller, PM., editors. Progressing behavior modification. Sycamore, IL: Sycamore Press; 1992. p. 184-214.

Prochaska JO, Velicer WF, DiClemente CC, Fava J. Measuring processes of change: Applications to the cessation of smoking. Journal of Consulting and Clinical Psychology. 1988; 56:520-528. [PubMed: 3198809]

Prochaska JO, Velicer WF, Fava JL, Rossi JS, Tsoh JY. Evaluating a population-based recruitment approach and a stage-based expert system intervention for smoking cessation. Addictive Behaviors. 2001; 26:583-602.10.1016/S0306-4603(00)00151-9 [PubMed: 11456079]

Prochaska JO, Velicer WF, Prochaska JM, Johnson J. Size, consistency and stability of stage effects for smoking cessation. Addictive Behaviors. 2004; 29:207-217.10.1016/S0306-4603(03)00086-8 [PubMed: 14667431]

Prochaska JO, Velicer WF, Redding CA, Rossi JS, Goldstein M, DePue J, et al. Stage-based expert systems to guide a population of primary care patients to quit smoking, eat healthier, prevent skin cancer, and receive mammograms. Preventive Medicine. 2005; 41:406-416.10.1016/j.ypmed. 2004.09.050 [PubMed: 15896835]

Redding CA, Prochaska JO, Paiva A, Rossi AP, Velicer W, Blissmer BJ, Greene GW, Robbins ML, Sun X. Baseline stage, severity, and effort effects differentiate stable smokers from maintainers and relapsers. Substance Use and Misuse. 2011; 00:1-11.10.3109/10826084.2011.565853 
Shiffman S, Waters AJ. Negative affect and smoking lapses: A prospective analysis. Journal of Consulting and Clinical Psychology. 2004; 72:192-201.10.1037/0022-006X.72.2.192 [PubMed: 15065954]

Sun X, Prochaska JO, Velicer WF, Laforge RG. Transtheoretical principles and processes for quitting smoking: A 24-month comparison of a representative sample of quitters, relapsers, and nonquitters. Addictive Behaviors. 2007; 32:2707-2726.10.1016/j.addbeh.2007.04.005 [PubMed: 17499935]

Vangeli E, Stapleton J, West R. Smoking intentions and mood preceding lapse after completion of treatment to aid smoking cessation. Patient Education and Counseling. 2010; 81:267-71.10.1016/ j.pec.2010.01.024 [PubMed: 20189745]

Velicer WF, DiClemente CC, Prochaska JO, Brandenberg N. A decisional balance measure for assessing and predicting smoking status. Journal of Personality and Social Psychology. 1985; 48:1279-1289.10.1037/0022-3514.48.5.1279 [PubMed: 3998990]

Velicer WF, DiClemente CC, Rossi JS, Prochaska JO. Relapse situations and self-efficacy: an integrative model. Addictive Behaviors. 1990; 15:271-283.10.1016/0306-4603(90)90070-E [PubMed: 2378287]

Velicer WF, Norman GJ, Fava JL, Prochaska JO. Testing 40 predictions from the Transtheoretical Model. Addictive Behaviors. 1999; 24:455-469.10.1016/S0306-4603(98)00100-2 [PubMed: 10466842]

Velicer WF, Prochaska JO, Redding CA, Rossi JS, Sun X, Rossi SR, et al. Efficacy of expert system interventions for employees to decrease smoking, dietary fat, and sun exposure [abstract]. International Journal of Behavioral Medicine. 2004; 11(suppl):277.

Velicer WF, Redding CA, Sun X, Prochaska JO. Demographic variables, smoking variables, and outcome across five studies. Health Psychology. 2007; 26:278287.10.3109/10826084.2011.565853 [PubMed: 17500614]

West, R. Theory of addiction. Oxford: Blackwell-Wiley Publishing; 2006. 


\section{Highlights}

- Participants aged 25-64 compared to those aged 18-24 were less likely to relapse at follow-up.

- Not being in a treatment group doubled the odds of relapsing at follow-up.

- Relapse occurred not solely due to smoking addiction severity, but due to immediate precursor factors such as temptations.

- Participants who had higher scores of Reinforcement Management and SelfReevaluation were more likely to relapse at follow-up. 


\section{Table 1}

Odds Ratios for baseline demographics and severity of smoking variables evaluating the chances of participants who relapsed vs. maintained.

\begin{tabular}{|c|c|c|c|c|}
\hline & \multirow[b]{2}{*}{$p$} & \multirow[b]{2}{*}{ Odds Ratio } & \multicolumn{2}{|c|}{$95 \% \mathrm{CI}$} \\
\hline & & & Lower & Upper \\
\hline Control Group & 0.00 & $2.17^{* * *}$ & 1.44 & 3.25 \\
\hline Female & 0.86 & 1.04 & 0.70 & 1.53 \\
\hline Non-White & 0.10 & 2.14 & 0.87 & 5.27 \\
\hline \multicolumn{5}{|l|}{ Education } \\
\hline College and/or Graduate School & 0.17 & 0.76 & 0.52 & 1.12 \\
\hline \multicolumn{5}{|l|}{ Marital Status } \\
\hline Married or Living with Partner & 0.82 & - & - & - \\
\hline Not Married & 0.56 & 1.18 & 0.68 & 2.04 \\
\hline Separated or Divorced & 0.51 & 0.83 & 0.48 & 1.44 \\
\hline Widowed & 1.00 & 0.00 & 0.00 & \\
\hline \multicolumn{5}{|l|}{ Age } \\
\hline $18-24$ & 0.05 & - & - & - \\
\hline $25-44$ & 0.01 & $0.43^{*}$ & 0.23 & 0.81 \\
\hline $45-64$ & 0.01 & $0.40^{*}$ & 0.2 & 0.8 \\
\hline $65+$ & 0.08 & 0.51 & 0.24 & 1.09 \\
\hline \multicolumn{5}{|l|}{ Daily Cigarette Use } \\
\hline$\unlhd$ & 0.20 & - & - & - \\
\hline 19-Oct & 0.38 & 1.28 & 0.74 & 2.24 \\
\hline $20-29$ & 0.05 & 1.74 & 1.00 & 3.04 \\
\hline $30+$ & 1.14 & 1.68 & 0.85 & 3.33 \\
\hline \multicolumn{5}{|l|}{ Time to First Cigarette of the Day } \\
\hline 15 minutes & 0.42 & - & - & - \\
\hline 30 minutes & 0.33 & 1.34 & 0.75 & 2.38 \\
\hline 60 minutes & 1.00 & 1.00 & 0.55 & 1.81 \\
\hline $1-10$ hours & 0.35 & 0.78 & 0.46 & 1.31 \\
\hline $10-1000$ hours & 0.74 & 0.85 & 0.33 & 2.19 \\
\hline \multicolumn{5}{|l|}{ Number of Quit Attempts } \\
\hline None & 0.19 & - & - & - \\
\hline $1-2$ & 0.16 & 1.41 & 0.87 & 2.26 \\
\hline $3-10$ & 0.03 & $1.70^{*}$ & 1.05 & 2.77 \\
\hline $11-98$ & 0.37 & 1.56 & 0.56 & 4.07 \\
\hline \multicolumn{5}{|l|}{ Longest Time Being Quit } \\
\hline 1 month & 0.15 & - & - & - \\
\hline $2-12$ months & 0.3 & 0.77 & 0.47 & 1.26 \\
\hline $12-36$ months & 0.59 & 0.87 & 0.52 & 1.46 \\
\hline $36-72$ months & 0.02 & $0.42^{*}$ & 0.2 & 0.89 \\
\hline
\end{tabular}

Addict Behav. Author manuscript; available in PMC 2016 March 01. 
Note. $\mathrm{CI}=$ confidence interval.

*** $p<.001$,

* $p<.05$. 
Table 2

Odds Ratios for TTM effort variables evaluating the chances of participants who relapsed vs. maintained.

\begin{tabular}{|c|c|c|c|c|}
\hline \multirow{2}{*}{ TTM Effort Variables } & \multirow{2}{*}{$p$} & \multirow{2}{*}{ Odds Ratio } & \multicolumn{2}{|c|}{$95 \% \mathrm{CI}$} \\
\hline & & & Lower & Upper \\
\hline \multicolumn{5}{|l|}{ Decisional Balance } \\
\hline Pros & 0.16 & 1.03 & 0.99 & 1.06 \\
\hline Cons & 0.94 & 1.00 & 0.97 & 1.03 \\
\hline \multicolumn{5}{|l|}{ Situational Temptations } \\
\hline Positive Social & 0.77 & 1.01 & 0.96 & 1.06 \\
\hline Negative Affect & 0.75 & 1.01 & 0.96 & 1.06 \\
\hline Habit Strength & 0.02 & $1.05^{*}$ & 1.01 & 1.10 \\
\hline Total & 0.00 & $1.06^{* *}$ & 1.03 & 1.10 \\
\hline \multicolumn{5}{|l|}{ Processes of Change } \\
\hline $\mathrm{CC}$ & 0.76 & 0.99 & 0.95 & 1.04 \\
\hline $\mathrm{CR}$ & 0.5 & 0.98 & 0.92 & 1.04 \\
\hline DR & 0.09 & 0.95 & 0.9 & 1.01 \\
\hline ER & 0.19 & 1.04 & 0.98 & 1.09 \\
\hline HR & 0.13 & 0.96 & 0.92 & 1.01 \\
\hline $\mathrm{RM}$ & 0.04 & $1.05^{*}$ & 1.00 & 1.10 \\
\hline SC & 0.18 & 0.97 & 0.92 & 1.02 \\
\hline SL & 0.72 & 0.99 & 0.94 & 1.04 \\
\hline SO & 0.9 & 1.00 & 0.95 & 1.05 \\
\hline SR & 0.01 & $1.08^{*}$ & 1.02 & 1.13 \\
\hline Experiential & 0.49 & 1.02 & 0.97 & 1.07 \\
\hline Behavioral & 0.31 & 0.97 & 0.92 & 1.03 \\
\hline Total & 0.63 & 0.96 & 0.96 & 1.03 \\
\hline
\end{tabular}

Note. $\mathrm{CI}=$ confidence interval.

* $p<.05$,

$* *$

$p<.00$.

$\mathrm{CC}=$ Counterconditioning, $\mathrm{CR}=$ Consciousness Raising, $\mathrm{DR}=$ Dramatic Relief, $\mathrm{ER}=$ Environmental Reevaluation, $\mathrm{HR}=$ Helping Relationship, $\mathrm{RM}=$ Reinforcement Management, $\mathrm{SC}=$ Stimulus Control, $\mathrm{SL}=$ Self-Liberation, $\mathrm{SO}=$ Social Liberation, $\mathrm{SR}=$ Self-Reevaluation. 